\title{
Optimal Timing and Antibiotic Prophylaxis in Periprosthetic Joint Infection (PJI): Literature Review and World Consensus (Part Five)
}

\author{
Javad Parvizi, ${ }^{1, *}$ Mohammad Ghazavi, ${ }^{2}$ and Members of Pre-Op Antibiotics Committee of \\ the Consensus Meeting ${ }^{3}$ \\ ${ }^{1}$ Rothman Institute, Thomas Jefferson University, Philadelphia, USA \\ ${ }^{2}$ Shafa Orthopedic Hospital, Iran University of Medical Sciences, Tehran, IR Iran \\ 3 William Arnold MD PhD; Katherine Belden MD, Goran Bicanic; Stefano Bini MD; Fabio Catani MD; Jiying Chen MD PhD; Mohammad Ghazavi MD FRCSC; Karine M. Godefroy MD; Erik \\ Hansen MD; Paul Holham MD; Hamid Hosseinzadeh MD; Kang II Kim MD; Klaus Kirketerp-Moller MD; Lars Lidgren MD PhD; Jian Hao Lin MD; Jess H. Lonner MD; Christopher Moore \\ MD; Panayiotis Papagelopoulos MD; Lazaros Poultsides MD MSc PhD; Khalid Saleh MD MSC FRCSC MHCM; Julia V. Salmon MD; Edward Schwarz PhD; Randi Silibovsky MD (US); Jose \\ Stuyck MD; Markus Vogt MD (International); Annette W. Dahl MD; Koji Yamada MD \\ *Corresponding author: Javad Parvizi, Rothman Institute, Thomas Jefferson University, Philadelphia, USA. Tel:+1-2673397813, Fax: +1-2155030580, E-mail: parvizi@aol.com
}

Received 2015 December 13; Accepted 2015 December 19.

\begin{abstract}
Context: There is a need to find the optimal doses and any need for weight adjustment in patients who have higher than standard BMI. There is also a need to determine if repeating doses of antibiotics is necessary when the surgery takes longer than usual.

Evidence Acquisition:Delegates in workgroup 3 of the consensus meeting on PJI reviewed English literature for relevant articles. 28 of 221 articles were relevant to the 2 following questions regarding perioperative antibiotic prophylaxis to prevent PJI.

Results: Preoperative antibiotics have different pharmacokinetics based on patient weight and should be weight-adjusted. An additional dose of antibiotic should be administered intraoperatively after two half-lives of the prophylactic agent. The general guidelines for frequency of intraoperative antibiotic administration are provided. We recommend that re-dosing of antibiotics be considered in cases of large blood volumeloss $(>2000 \mathrm{cc}$ ) and fluid resuscitation $(>2000 \mathrm{cc}$ ). As these are independent variables, re-dosing should be considered as soon as the first of these parameters are met.

Conclusions: Recommendations for need for weight adjustment doses and repeat of doses in longer duration surgeries in terms of perioperative antibiotic prophylaxis in hip and knee arthroplasty were provided based on evidences in the literature and consensus of expert delegates from consensus meeting.

Keywords: Infection, Joints, Periprosthetic, Arthroplasty
\end{abstract}

\section{Context}

Decision making in adjusting the doses of antibiotic prophylaxis based on patients' weight and need for repeating doses in longer duration surgeries need to be defined.

\section{Evidence Acquisition}

From November 2012 till August 2013, 400 delegates from all over the world formed 15 workgroups to review the current literature and find high level evidence for all issues related to PJI. Workgroup No. 3 (authors) was assigned to review current literature on perioperative antibiotics. The goal was to find answers and recommendations for more than 264 questions based on the high level evidence if present or reach to a consensus when there is a lack of high level evidence.

After 10 months of hard work by delegates from 58 countries and 100 societies, relevant publications reviewed, communications exchanged and finally a draft was prepared to be presented for vote at the final meeting on 1st of August 2013. The draft included recommendations for management on the basis of high level of evidence if present. Oth- erwise the cumulative wisdom of 400 delegates from 58 countries and over 100 societies used to reach consensus about practices lacking higher level of evidence.

\section{Results}

\subsection{Question 15}

For surgeries of longer duration, when should an additional dose of antibiotic be administered intraoperatively?

\subsection{Consensus}

An additional dose of antibiotic should be administered intraoperatively after two half-lives of the prophylactic agent. The general guidelines for frequency of intraoperative antibiotic administration are provided. We recommend that redosing of antibiotics be considered in cases of large blood volume loss (>2000 cc) and fluid resuscitation (>2000 cc). As these are independent variables, re-dosing should be considered as soon as the first of these parameters are met.

Copyright (C) 2016, Iran University of Medical Sciences. This is an open-access article distributed under the terms of the Creative Commons Attribution-NonCommercial 4.0 International License (http://creativecommons.org/licenses/by-nc/4.0/) which permits copy and redistribute the material just in noncommercial usages, provided the original work is properly cited. 


\subsection{Delegate Vote}

The results were as follows: agree: $94 \%$; disagree: 5\%; abstain: $1 \%$ (strong consensus).

\subsection{Justification}

In cases of large blood volume loss and fluid resuscitation there is a remarkable loss of the prophylactic agent that can result in levels below the MIC. The same is true for longer surgeries that extend beyond the half-life of the agent. Thus, additional antibiotic treatment is needed to re-establish antibiotic levels that exceed the MIC. An additional dose of antibiotic has been shown to reduce SSI rates in cardiac patients and should be administered intraoperatively after two half-lives of the prophylactic agent (1-3).

The AAOS recommendations for the use of IV antibiotic prophylaxis in primary $\mathrm{TJA}$, recommendation 2, states that timing and dosage of antibiotic administration should be such to optimize the efficacy of the therapy. Both the IDSA and AAOS state that "Additional intraoperative doses of antibiotic are advised when the duration of the procedure exceeds one to two times the antibiotic's half-life or when there is significant blood loss during the procedure".

The general guidelines for frequency of intraoperative antibiotic administration are as follows: cefazolin every 2 - 5 (4) hours, cefuroxime every 3 - 4 hours, clindamycin every 3 - 6 hours, isoxazoyl penicillin every 3 hours, and vancomycin every 6 - 12 hours (4-6).

In a prospective multicenter study exploring the relationship between timing, duration, and intraoperative redosing of surgical antimicrobial prophylaxis and the risk of SSI, Steinberg et al. determined that intraoperative dosing was associated with a lower infection risk only when the preoperative antibiotic was given in the recommended time frame. In 1,062 (24\%) cases, the surgical procedure lasted for at least 4 hours. Because of a longer half-life and the reduced need for redosing, cases that received vancomycin or fluoroquinolones were excluded from the analysis of the impact of redosing on infection risk $(n=372)$. Intraoperative redosing was given in $21 \%$ of 690 of these long operations. Of the group that had a surgical procedure with a duration of $>4$ hours and who received the preoperative dose within one hour, 2 of 112 (1.8\%) patients who were redosed intraoperatively developed infection, compared to 22 of 400 (5.5\%) of those who were not re-dosed (OR: 3.08; $\mathrm{P}=0.06)(7)$.

Scher randomized 801 patients undergoing clean contaminated operations to one of three antibiotic regimens: $1 \mathrm{~g}$ of cefazolin preoperatively, $1 \mathrm{~g}$ of cefazolin preoperatively and another dose 3 hours later, and $1 \mathrm{~g}$ of cefotetan preoperatively. While all regimens demonstrated similar wound infection rates for surgeries lasting less than 3 hours, for those that exceeded 3 hours, the group that only received the single preoperative cefazolin dose had a statistically significant higher wound infection rate than those who received the second cefazolin dose (6.1\% vs 1.3\%, P<0.01) (8).

Shapiro et al. performed a placebo-controlled RCT to test the efficacy of perioperative cefazolin in preventing infection after abdominal or vaginal hysterectomy. The authors sub-analyzed the effect of surgery duration on the efficacy of perioperative prophylaxis by calculating adjusted relative odds of infection with and without prophylaxis for different durations of surgery and found that the efficacy of prophylaxis diminishes rapidly with increasing length of surgery; by 3 hours, 20 minutes prophylaxis had no measurable effect $(\mathrm{OR}=1)(9)$.

Polk et al. prospectively analyzed the antibiotic levels of 3 cephalosporins (cefazolin, cephaloridine, and cephalothin) given as a single preoperative dose and found that acceptable concentrations of cefazolin were maintained near the incision site until 3 hours postadministration, whereas cephalothin did not maintain wound levels consistent with effective antimicrobial activity (10).

Ohge et al. prospectively examined the pancreatic tissue concentrations of cefazolin in 10 patients undergoing pancreatectomy and determined the optimal intraoperative time to repeat the dose of cefazolin. Based on their results, the authors recommended a second dose of kefzol be given 3 hours after first administration in order to maintain adequate levels of antibiotic activity. They measured MIC for 4 bacterial species, namely 360 isolates of MSSA, 204 isolates of K. pneuomoniae, 314 isolates of E. coli, and 30 isolates of streptococci species; and measured tissue levels of cefazolin. Antibiotic concentrations in adipose tissue and peritoneum 3 hours after administration of kefzol were lower than the MIC 80 for K. pneumoniae, E. coli, and streptococcal species (7).

In a retrospective review of 131 patients with primary colorectal cancer in prolonged operations exceeding 4 hours, the surgical wound infection rates were $8.5 \%$ and $26.5 \%$ respectively for those with $(n=47)$ and without ( $n$ $=49$ ) intraoperative repeated dosing, which were significantly different based on both a univariate $(\mathrm{P}=0.031)$ and a multivariate analysis $(\mathrm{P}=0.008)(11)$.

Zanetti et al. retrospectively compared the risk of SSIs in 1,548 patients who underwent cardiac surgery lasting $>$ 240 minutes after preoperative administration of cefazolin prophylaxis. The overall risk of SSI was similar among patients with (43 (9.4\%) of 459 ) and without (101 (9.3\%) of 1089) intraoperative redosing (OR 1.01, 95\% CI 0.7 - 1.47). However, redosing was beneficial in procedures lasting > 400 minutes; infection occurred in 14 (7.7\%) of 182 patients with redosing and in $32(16.0 \%)$ of 200 patients without (adjusted OR $0.44,95 \%$ CI 0.23 - 0.86). Intraoperative redosing of cefazolin was associated with a $16 \%$ reduction in the overall risk for SSI after cardiac surgery, including procedures lasting $>240$ minutes $(2,3)$.

\subsection{Blood Loss}

Swoboda et al. attempted to determine the effect of intraoperative blood loss on prophylactic cefazolin and gentamicin serum and tissue concentration in a prospective study of elective spinal surgical procedures with expected 
Parvizi J et al.

large blood loss. At 60 minutes after the incision, blood loss correlated with cefazolin tissue concentrations $(\mathrm{r}=$ $-0.66, P=0.05)$ and the clearance of gentamicin from the tissues $(\mathrm{r}=0.82, \mathrm{P}=0.01)$. Based on their measured pharmacokinetic values, additional doses of cefazolin should be administered when the operation exceeds 3 hours and blood loss is greater than $1500 \mathrm{~mL}$. A dose of gentamicin greater than $1.8 \mathrm{mg} / \mathrm{kg}$ should be administered more than 30 minutes prior to the surgical incision (12).

\subsection{Blood Loss/Volume Replacement}

Markantonis et al. investigated the effects of surgical blood loss and fluid volume replacement on gentamicin concentrations in serum and in 3 tissue types (subcutaneous fat, epiploic fat and colonic wall) in patients in undergoing colorectal surgery. Gentamicin was administered at a standard dose of $2 \mathrm{mg} / \mathrm{kg}$ and blood and tissue samples were obtained concurrently at specific times throughout each procedure. The mean concentration at first surgical incision was 7.83 (0.82) $\mathrm{fEg} / \mathrm{mL}$ and decreased to $2.60(0.28)$ $\mathrm{fE} / \mathrm{mL}$ at skin closure, resulting in borderline effectiveness even for susceptible gram-negative microorganisms (MIC1.0). A strong negative correlation was found between the intravenously administered fluids and gentamicin concentrations in serum and tissues $(\mathrm{P}=0.04)(13)$.

Klekamp et al. prospectively studied orthopaedic patients with either large or small blood loss who also received vancomycin prophylaxis to determine the effect of intraoperative volume shifts on serum vancomycin concentrations. There were 6 index patients in the large blood loss group (greater than $2 \mathrm{~L}$ ) and 7 in the control group (less than $2 \mathrm{~L}$ ), with mean estimated blood loss for index and controls was $4.4 \mathrm{~L}$ and $1.0 \mathrm{~L}$; and the mean intraoperative fluid resuscitation, excluding blood products, was $12.4 \mathrm{~L}$ and $5.1 \mathrm{~L}$ respectively. There was a modest inverse correlation between blood loss and the intraoperative serum half-life of vancomycin. Although controls maintained slightly higher intraoperative vancomycin concentrations at each time point, there was no statistically significant difference between the groups with regard to absolute concentrations or rate of decline. After 8 hours, the serum concentration of vancomycin exceeded the MIC-90 for S. aureus by approximately eightfold in all but one case patient, who was morbidly obese and had massive blood loss. Thus blood loss during orthopaedic procedures has a minimal effect on the intraoperative kinetics of vancomycin and administering vancomycin every 8 to 12 hours seems appropriate for most patients (14). Two well-controlled studies of surgical prophylaxis with cefazolin similarly demonstrated minimal effects of blood loss on drug concentrations during THA and spine fusion procedures. Meter et al. examined the effect of intraoperative blood loss and volume resuscitation during THA on serum levels of cefazolin in 18 patients. At 4 hours after administration, the serum level of cefazolin was $45 \mathrm{mcg} / \mathrm{mL}$, which far exceeded the MIC for S. aureus $(0.5 \mathrm{mcg} / \mathrm{mL})$, despite an aver- age intraoperative blood loss of $1137 \pm 436 \mathrm{~mL}$. This led the authors to conclude that even with blood losses of $2 \mathrm{~L}$, it is not necessary to redose cefazolin any earlier than 4 hours in order to maintain the MIC for most common infecting organisms (15). The authors repeated the study in 19 patients undergoing instrumented posterior spinal fusion and found that there was no significant difference between preoperative and intraoperative cefazolin clearance and there was no correlation between blood loss and cefazolin level(16).

\subsection{Question 16}

Should preoperative antibiotic doses be weight-adjusted?

\subsection{Consensus}

Preoperative antibiotics have different pharmacokinetics based on patient weight and should be weight-adjusted.

\subsection{Delegate Vote}

The results were as follows: agree: $95 \%$; disagree: $4 \%$; abstain: $1 \%$ (strong consensus).

\subsection{Justification}

Because of the relative unpredictability of pharmacokinetics in obese individuals, doses are best estimated on the basis of specific studies for individual drugs carried out in this population. Only a few antibiotics (aminoglycosides, vancomycin, daptomycin, and linezolid) have been studied in the obese population.

AAOS recommendation for the use of IV antibiotic prophylaxis in primary TJA, recommendation 2, states that gtiming and dosage of antibiotic administration should optimize the efficacy of the therapy. Dose amount should be proportional to patient weight; for patients $>80 \mathrm{~kg}$, the doses of cefazolin should be doubled.

The recommended dose of cefazolin is based on patient's body mass index (BMI), with $1.0 \mathrm{~g}$ for people who weigh $<$ $80 \mathrm{~kg}$ and $2.0 \mathrm{~g}$ for those who weigh $>80 \mathrm{~kg}$. The adult dose of cefuroxime is $1.5 \mathrm{~g}$. The recommended dose of clindamycin is 600 to $900 \mathrm{mg}$. The recommended dose of vancomycin, which is based on BMI, is $10-15 \mathrm{mg} / \mathrm{kg}$, up to a limit of $1 \mathrm{~g}$, in patients with normal renal function (17). However, there is literature to support the use of higher doses of vancomycin, with emphasis that doses $>4 \mathrm{~g}$ /day have been associated with increased risk of nephrotoxicity.

A trough level is obtained prior to the fourth scheduled dose and in certain occasions there may be a need to shorten dosing interval to maintain therapeutic trough level (e.g. q12 hour to q8 hour dosing).

Because $30 \%$ of adipose is water, an empirical approach is to use the Devine formula to calculate ideal body weight (IBW), to which is added a dosing weight correction factor (DWCF) of 0.3 times the difference between actual body weight $(\mathrm{ABW})$ and IBW $(\mathrm{IBW}+0.3 \times[\mathrm{ABWIBW}])$ to arrive at a weight on which to base dosage of hydrophilic antibiotics. No studies confirm this approach for 
fA-lactam drugs. Clinical studies suggest a DWCF of 0.4 for aminoglycosides and 0.45 for quinolones (18).

For aminoglycosides, some suggest using ABW using a dosing correction factor $(19,20)$ while others suggest dosing based on lean body weight (LBW) with appropriate monitoring with the first dose (21). Current guidelines for vancomycin administration are based on loading doses of vancomycin on the total body weight (TBW) of the patient and maintenance doses on the calculated creatinine clearance $(\mathrm{CrCl})$ of the patient $(20,22)$. However, deciding whether to base $\mathrm{CrCl}$ calculations on $\mathrm{ABW}$, IBW, or another measure is still to be determined. As a general rule, obese and morbidly obese patients require higher doses of cephalosporin to achieve similar outcomes; however, there are fewer absolute dosing recommendations. At least one study demonstrated that a dose of $2 \mathrm{~g}$ of cephazolin should provide adequate levels for at least 4 hours, even in super morbid obesity (MO) $\left(\mathrm{BMI}=50 \mathrm{~kg} / \mathrm{m}^{2}\right)(23)$.

Other studies confirm that vancomycin should be given on the basis of ABW, with dosage adjustments based on serum concentrations (24) whereas aminoglycoside dosing requires calculation of adjusted body weight via a correction factor (25).

Forse et al. conducted a prospective RCT in MO patients undergoing gastroplasty and found that the blood and tissue levels of cefazolin were significantly lower for all MO patients who received $1 \mathrm{~g}$ cefazolin compared with the blood and tissue levels of the drug found in normal weight patients who received a similar dose of antibiotic. Moreover, the MO patients who only received $1 \mathrm{~g}$ of cefazolin had antibiotic levels below the MIC of $2 \mathrm{mcg} / \mathrm{mL}$ for gram-positive cocci and $4 \mathrm{mcg} / \mathrm{mL}$ for gram-negative rods. The serum and tissue concentrations were adequate only when $2 \mathrm{~g}$ of cefazolin were administered. Also, relative to 1 $\mathrm{g}$, the administration of cefazolin $2 \mathrm{~g}$ decreased the wound infection rate from $16.5 \%$ to $5.6 \%$ in these MO patients (26).

Van Kralingen et al. studied the influence of body weight measures and age on pharmacokinetic parameters and evaluated unbound cefazolin concentrations over time in obese patients.

Twenty MO patients $\left(\mathrm{BMI}=38-79 \mathrm{~kg} / \mathrm{m}^{2}\right)$ were studied following the administration of $2 \mathrm{~g}$ of cefazolin at induction of anesthesia. Blood samples were collected up to 4 hours post dosing to determine the total and unbound plasma cefazolin concentrations. Cefazolin clearance was $4.2 \pm 1.0$ $\mathrm{L} / \mathrm{h}$ and showed a negative correlation with age $(\mathrm{P}=0.003)$ but not with body weight measures $(\mathrm{P}>0.05)$. In all patients, unbound cefazolin concentrations remained above $1 \mathrm{mg} / \mathrm{L}$ (MIC 90) of MSSA until 4 hours post dosing (27).

Ho et al. attempted to determine an optimal dosing regimen for cefazolin as a prophylactic antibiotic in surgery for patients with MO. Twenty-five patients undergoing elective surgical procedures were given a single dose of cefazolin: 10 with $\mathrm{MO}\left(\mathrm{BMI}=40-50 \mathrm{~kg} / \mathrm{m}^{2}\right)$ received $2 \mathrm{~g}$ via intravenous push (IVP), 5 with MO received $2 \mathrm{~g}$ via 30 minute infusion, 5 with super morbid obesity (SMO, BMI $>50 \mathrm{~kg}$ / $\mathrm{m}^{2}$ ) received $2 \mathrm{~g}$ via infusion, and 5 with SMO received $3 \mathrm{~g}$ via infusion. The protective duration, determined using a pharmacodynamic target for $\mathrm{fT}>\mathrm{MIC}$ of $70 \%$, was 5.1 hours for MO2-IVP, 4.8 hours for MO2-INF, 5.8 hours for SMO2-INF, and 6.8 hours for SMO3-INF. The authors concluded that a single $2 \mathrm{~g}$ dose of cefazolin appears to provide antibiotic exposure sufficient for most common general surgical procedures of $<5$ hours duration regardless of BMI (23).

In contrast, Edmiston et al. concluded that $2 \mathrm{~g}$ of cefazolin may not be sufficient for patients with a BMI $>50 \mathrm{~kg} /$ $\mathrm{m}^{2}$, based upon measurements of total serum concentrations in morbidly obese patients undergoing gastric bypass. The authors assigned 38 patients to one of $3 \mathrm{BMI}$ groups: A) BMI $\left.=40-49 \mathrm{~kg} / \mathrm{m}^{2} ;(\mathrm{n}=17), \mathrm{B}\right) \mathrm{BMI}=50-59 \mathrm{~kg}$ / $\mathrm{m}^{2} ;(\mathrm{n}=11)$, and C) BMI $\geq 60 \mathrm{~kg} / \mathrm{m}^{2} ;(\mathrm{n}=10)$ and measured serum and tissue concentrations of cefazolin. They determined that therapeutic tissue levels were only achieved in $48.1 \%, 28.6 \%$, and $10.2 \%$ in groups $\mathrm{A}, \mathrm{B}$, and $\mathrm{C}$ respectively. The authors measured concentrations in the serum skin, adipose tissue, and omentum, but did not evaluate unbound cefazolin concentrations, which may be expected to migrate across tissues rapidly (Table 1), (28).

\begin{tabular}{|c|c|c|c|}
\hline $\begin{array}{l}\text { Antimicrobial/Actual Body } \\
\text { Weight, kg }\end{array}$ & Recommended Dose, mg & $\begin{array}{c}\text { Perioperative } \\
\text { Redosing Schedule }\end{array}$ & Indication \\
\hline Cefazolin & & & Primary perioperative prophylaxis \\
\hline$<60$ & 1000 & every $4 \mathrm{~h}$ & \\
\hline $60-120$ & 2000 & every $4 \mathrm{~h}$ & \\
\hline$>120$ & 3000 & every $4 \mathrm{~h}$ & \\
\hline Cefuroxime & & & primary perioperative prophylaxis \\
\hline No adjustments & 1500 & every $4 \mathrm{~h}$ & \\
\hline \multicolumn{4}{|l|}{ Vancomycin } \\
\hline $\begin{array}{l}\text { Weight based dosing } \\
\text { recommended } 15 \mathrm{mg} / \mathrm{kg} \\
\text { (Maximum dose } 2000 \mathrm{mg} \text { ) }\end{array}$ & $\begin{array}{l}\text { One dose pre-op, one dose } 12 \\
\text { hours post-op, one dose } 24 \\
\text { hours postop }\end{array}$ & every $6-12 \mathrm{~h}$ & $\begin{array}{l}\text { perioperative prophylaxis for current MRSA carriers and/ } \\
\text { or patients with lactam allergy }\end{array}$ \\
\hline \multicolumn{4}{|l|}{ Clindamycin } \\
\hline No adjustments & 900 & every $3 \mathrm{~h}$ & Perioperative prophylaxis for patients with lactam allergy \\
\hline \multicolumn{4}{|l|}{ Teicoplanin } \\
\hline No adjustments & 400 & NA & $\begin{array}{l}\text { Perioperative prophylaxis for current MRSA carriers and/ } \\
\text { or patients with lactam allergy }\end{array}$ \\
\hline
\end{tabular}




\section{Conclusions}

\subsection{Question 15}

For surgeries of longer duration, when should an additional dose of antibiotic be administered intraoperatively?

\subsection{Consensus}

An additional dose of antibiotic should be administered intraoperatively after two half-lives of the prophylactic agent. The general guidelines for frequency of intraoperative antibiotic administration are provided. We recommend that re-dosing of antibiotics be considered in cases of large blood volume loss (>2000 cc) and fluid resuscitation (>2000 cc). As these are independent variables, re-dosing should be considered as soon as the first of these parameters are met.

\subsection{Delegate Vote}

The results were as follows: agree: 94\%; disagree: $5 \%$; abstain: $1 \%$ (strong consensus).

\subsection{Question 16}

Should preoperative antibiotic doses be weight-adjusted?

\subsection{Consensus}

Preoperative antibiotics have different pharmacokinetics based on patient weight and should be weight-adjusted.

\subsection{Delegate Vote}

The results were as follows: agree: $95 \%$; disagree: $4 \%$; abstain: $1 \%$ (strong consensus).

\section{References}

1. Bratzler DW, Houck PM, Surgical Infection Prevention Guidelines Writers W, American Academy of Orthopaedic S, American Association of Critical Care N, American Association of Nurse A et al. Antimicrobial prophylaxis for surgery: an advisory statement from the National Surgical Infection Prevention Project. Clin Infect Dis. 2004;38(12):1706-15. doi: 10.1086/421095. [PubMed: 15227616]

2. Zanetti G, Giardina R, Platt R. Intraoperative redosing of cefazolin and risk for surgical site infection in cardiac surgery. Emerg Infect Dis. 2001;7(5):828-31. doi:10.3201/eid0705.017509. [PubMed: 11791504]

3. Zanetti G, Goldie SJ, Platt R. Clinical consequences and cost of limiting use of vancomycin for perioperative prophylaxis: example of coronary artery bypass surgery. Emerg Infect Dis. 2001;7(5):820-7. doi: 10.3201/eid0705.010508. [PubMed:11747694]

4. Prokuski L. Prophylactic antibiotics in orthopaedic surgery. J Am Acad Orthop Surg. 2008;16(5):283-93. [PubMed: 18460689]

5. Fletcher N, Sofianos D, Berkes MB, Obremskey WT. Prevention of perioperative infection. J Bone Joint Surg Am. 2007;89(7):1605-18. doi:10.2106/JBJS.F.00901. [PubMed:17606802]

6. Dellinger EP, Gross PA, Barrett TL, Krause PJ, Martone WJ, McGowan JJ, et al. Quality standard for antimicrobial prophylaxis in surgical procedures. The Infectious Diseases Society of America. Infect Control Hosp Epidemiol.1994;15(3):182-8. [PubMed: 8207176]

7. Ohge H, Takesue Y, Yokoyama T, Murakami Y, Hiyama E, Yokoya- ma Y, et al. An additional dose of cefazolin for intraoperative prophylaxis. Surg Today. 1999;29(12):1233-6. [PubMed:10639702]

8. Scher KS. Studies on the duration of antibiotic administration for surgical prophylaxis. Am Surg. 1997;63(1):59-62. [PubMed: 8985073]

9. Shapiro M, Munoz A, Tager IB, Schoenbaum SC, Polk BF. Risk factors for infection at the operative site after abdominal or vaginal hysterectomy. N Engl J Med. 1982;307(27):1661-6. doi:10.1056| NEJM198212303072701. [PubMed: 6755254]

10. Polk HJ, Trachtenberg L, Finn MP. Antibiotic activity in surgica incisions. The basis of prophylaxis in selected operations. JAMA. 1980;244(12):1353-4. [PubMed: 7411809]

11. Morita S, Nishisho I, Nomura T, Fukushima Y, Morimoto T, Hiraoka N, et al. The significance of the intraoperative repeated dosing of antimicrobials for preventing surgical wound infection in colorectal surgery. Surg Today. 2005;35(9):732-8. doi: 10.1007| s00595-0 05-3026-3. [PubMed:16133667]

12. Swoboda SM, Merz C, Kostuik J, Trentler B, Lipsett PA. Does intraoperative blood loss affect antibiotic serum and tissue concentrations? Arch Surg. 1996;131(11):1165-71. [PubMed: 8911256]

13. Markantonis SL, Kostopanagiotou G, Panidis D, Smirniotis V, Voros D. Effects of blood loss and fluid volume replacement on serum and tissue gentamicin concentrations during colorectal surgery. Clin Ther. 2004;26(2):271-81. [PubMed:15038949]

14. Klekamp JW, DiPersio D, Haas DW. No influence of large volume blood loss on serum vancomycin concentrations during orthopedic procedures. Acta Orthop Scand. 1999;70(1):47-50. [PubMed: 10191748]

15. Meter JJ, Polly DJ, Brueckner RP, Tenuta JJ, Asplund L, Hopkinson WJ. Effect of intraoperative blood loss on the serum level of cefazolin in patients managed with total hip arthroplasty. A prospective, controlled study. J Bone Joint Surg Am. 1996;78(8):1201-5. [PubMed: 8753712]

16. Polly DJ, Meter JJ, Brueckner R, Asplund L, van Dam BE. The effect of intraoperative blood loss on serum cefazolin level in patients undergoing instrumented spinal fusion. A prospective, controlled study. Spine (Phila Pa 1976).1996;21(20):2363-7. [PubMed: 8915072]

17. Gilbert DN. The Sanford guide to antimicrobial therapy.Vienna: Antimicrobial Therapy; 2002.

18. Wurtz R, Itokazu G, Rodvold K. Antimicrobial dosing in obese patients. Clin Infect Dis. 1997;25(1):112-8. [PubMed: 9243045]

19. Leader WG, Tsubaki T, Chandler MH. Creatinine-clearance estimates for predicting gentamicin pharmacokinetic values in obese patients. Am J Hosp Pharm. 1994;51(17):2125-30. [PubMed: 7985687]

20. Janson B, Thursky K. Dosing of antibiotics in obesity. Curr Opin Infect Dis. 2012;25(6):634-49. doi: 10.1097/QCO.0b013e328359a4c1. [PubMed: 23041773]

21. Begg EJ, Barclay ML, Duffull SB. A suggested approach to oncedaily aminoglycoside dosing. Br J Clin Pharmacol.1995;39(6):6059. [PubMed: 7654477]

22. Truong J, Levkovich BJ, Padiglione AA. Simple approach to improving vancomycin dosing in intensive care: a standardised loading dose results in earlier therapeutic levels. Intern Med J. 2012;42(1):23-9. doi: 10.1111/j.1445-5994.2011.02459.x. [PubMed: 22276559]

23. Ho VP, Nicolau DP, Dakin GF, Pomp A, Rich BS, Towe CW, et al. Cefazolin dosing for surgical prophylaxis in morbidly obese patients. Surg Infect (Larchmt). 2012;13(1):33-7. doi: 10.1089/ sur.2010.097. [PubMed: 22316145]

24. Rybak MJ, Lomaestro BM, Rotschafer JC, Moellering RC, Craig WA, Billeter M, et al. Vancomycin therapeutic guidelines: a summary of consensus recommendations from the infectious diseases Society of America, the American Society of Health-System Pharmacists, and the Society of Infectious Diseases Pharmacists. Clin Infect Dis. 2009;49(3):325-7. doi: 10.1086/600877. [PubMed:19569969]

25. Traynor AM, Nafziger AN, Bertino JJ. Aminoglycoside dosing weight correction factors for patients of various body sizes. Antimicrob Agents Chemother. 1995;39(2):545-8. [PubMed: 7726530]

26. Forse RA, Karam B, MacLean LD, Christou NV. Antibiotic prophylaxis for surgery in morbidly obese patients. Surgery. 1989;106(4):750-6. [PubMed: 2799651] 
27. van Kralingen S, Taks M, Diepstraten J, van de Garde EM, van Dongen EP,Wiezer MJ, etal. Pharmacokinetics and protein binding of cefazolin in morbidly obese patients. Eur J Clin Pharmacol. 2011;67(10):98592. doi: 10.1007/s00228-011-1048-x. [PubMed: 21499760]
28. Edmiston CE, Krepel C, Kelly H, Larson J, Andris D, Hennen C, et al. Perioperative antibiotic prophylaxis in the gastric bypass patient: do we achieve therapeutic levels? Surgery. 2004;136(4):73847. doi:10.1016/j.surg.2004.06.022. [PubMed:15467657] 